\title{
Complementary role of transoesophageal echocardiography to coronary angiography in the assessment of coronary artery anomalies
}

\author{
P J Giannoccaro, R A Sochowski, B C Morton, K-L Chan
}

University of Ottawa

Heart Institute,

Ottawa, Ontario, Canada

P J Giannoccaro

R A Sochowski

B C Morton

K-L Chan

Correspondence to

Dr K-L Chan, University of

1053 Carling Avenue,

H-210 Ottawa, Ontarid
Canada K1Y 4E9.

Accepted for publication

10 November 1992
Ottawa Heart Institute,

\begin{abstract}
Objectives-To examine the role of transoesophageal echocardiography in the assessment of patients with coronary artery anomalies.

Background-Coronary artery anomalies are difficult to detect clinically. Most are benign but some may produce symptoms that can be life threatening. Until recently the non-invasive assessment of coronary artery anomalies has been limited.

Methods-The data base of transoesophageal echocardiographic studies
\end{abstract}

Table 1 Clinical profile of the six patients with coronary artery disease

\begin{tabular}{lllllll}
\hline Patient & Age & Sex & Murmur & CAD & $\begin{array}{l}\text { Presenting } \\
\text { Symptoms }\end{array}$ & Surgery \\
\hline 1 & 58 & M & 0 & 0 & Dyspnoea & + \\
2 & 48 & M & + & + & Angina & + \\
3 & 61 & M & 0 & + & Angina & + \\
4 & 58 & M & 0 & + & Angina & + \\
5 & 40 & F & + & 0 & Angina & + \\
6 & 63 & F & + & 0 & Endocarditis & + \\
\hline
\end{tabular}

$\mathrm{CAD}$, atherosclerotic coronary artery disease.

Table 2 Echocardiographic and angiographic findings in patients with coronary artery anomalies

\begin{tabular}{|c|c|c|c|}
\hline Patient & $T T E$ & TOE & Angio \\
\hline 1 & $\begin{array}{l}\text { AI, MR, } \\
\text { Dilated LV, } \\
\text { RWMA }\end{array}$ & $\begin{array}{l}\text { Ectopic origin of LCA } \\
\text { from right sinus of } \\
\text { Valsalva coursing } \\
\text { between aorta and MPA, } \\
\text { AI, MR, RWMA }\end{array}$ & $\begin{array}{l}\text { Ectopic origin of LCA } \\
\text { from right sinus of } \\
\text { Valsalva, } \\
\text { course not seen }\end{array}$ \\
\hline 2 & Negative & $\begin{array}{l}\text { Dilated and tortuous LCx } \\
\text { with fistula to LV, } \\
\text { hypokinetic } \\
\text { inferior wall, } \\
\text { mild MR }\end{array}$ & $\begin{array}{l}\text { Dilated, tortuous LCx } \\
\text { with fistula coursing } \\
\text { posteriorly; drainage } \\
\text { site not identified, } \\
\text { CAD }\end{array}$ \\
\hline 3 & Negative & $\begin{array}{l}\text { Dilated LCA with fistula } \\
\text { from LCx coursing } \\
\text { between LA and aorta, } \\
\text { around SVC, and draining } \\
\text { into RPA }\end{array}$ & $\begin{array}{l}\text { Dilated LM and LCx, } \\
\text { fistula from LCx seen } \\
\text { but drainage site not } \\
\text { identified }\end{array}$ \\
\hline 4 & Negative & $\begin{array}{l}\text { Dilated, tortuous LCx } \\
\text { with fistula to the } \\
\text { posterior aspect of } \\
\text { proximal RPA, } \\
\text { dilated RCA supplying } \\
\text { collaterals to LCx }\end{array}$ & $\begin{array}{l}\text { Dilated, tortuous LCx } \\
\text { with fistula coursing } \\
\text { posteriorly probably } \\
\text { draining into RPA } \\
\text { or LA, } \\
\text { dilated RCA supplying } \\
\text { collaterals to LCx, } \\
\text { dilated SVG to } \\
\text { marginal }\end{array}$ \\
\hline 5 & $\begin{array}{l}\text { Dilated RCA with } \\
\text { fistula to RV }\end{array}$ & $\begin{array}{l}\text { Dilated tortuous RCA and } \\
\text { PIV branch with fistula } \\
\text { to RV apex, } \\
\text { LCA not seen }\end{array}$ & $\begin{array}{l}\text { Ectopic origin of LCA } \\
\text { from MPA, } \\
\text { dilated, tortuous RCA } \\
\text { supplies collaterals } \\
\text { to dilated LAD } \\
\text { (QP:QS = 2:1) }\end{array}$ \\
\hline 6 & $\begin{array}{l}\text { Aortic } \\
\text { insufficiency }\end{array}$ & $\begin{array}{l}\text { Vegetation on AoV, } \\
\text { dilated RCA with } \\
\text { fistula to SVC }\end{array}$ & $\begin{array}{l}\text { Dilated, tortuous RCA } \\
\text { with fistula to SVC } \\
\text { (QP:QS = 1·2:1) }\end{array}$ \\
\hline
\end{tabular}

AI, aortic insufficiency; Angio, coronary angiography, Aov, aortic valve; CAD, atherosclerotic coronary artery disease; LA, left atrium; LCA, left coronary artery; LCx, left circumflex; LM, left main; LV, left ventricle; MPA, main pulmonary artery; MR, mitral regurgitation; PIV, posterior interventricular artery; $Q P: Q S$, pulmonary to systemic shunt ratio; $R C A$, right coronary artery; RPA, right pulmonary artery; RV, right ventricle; RWMA, regional wall motion abnor-
mality; SVC, superior vena cava; SVG, saphenous vein graft; TOE, transoesophageal echocarmality; SVC, superior vena cava; SVG, saphenous
diography; TTE, transthoracic echocardiography. performed between September 1988 and April 1991 were reviewed to identify all cases of coronary artery anomalies. There were six patients with such anomalies who had also had coronary angiography. The findings of these two imaging techniques were analysed to determine whether transoesophageal echocardiography added useful data in these cases.

Results-Of the six patients, the coronary anomaly was discovered during angiography in four patients, during a transthoracic echocardiographic study in one patient, and as an incidental finding in the other patient. Aberrant origins of the left coronary artery were detected in two patients, and coronary artery fistulae were present in the other four. Transoesophageal echocardiography provided unique information on the course of an aberrant left coronary artery in one patient and the precise location of drainage sites of coronary artery fistulas in three patients.

Conclusion-Transoesophageal echocardiography was complementary to angiography in the assessment of coronary artery anomalies. It can locate and delineate the course of an ectopic coronary artery and the drainage site of a coronary fistula. These anatomical data can be crucial to the management of these patients.

(Br Heart F 1993;70:70-74)

The incidence of coronary artery anomalies identified during coronary angiography is $0 \cdot 6 \%-1 \cdot 3 \% .^{1}$ Most coronary artery anomalies are benign and are incidental findings but some may produce symptoms or can be potentially life threatening. There are two main groups of coronary artery anomalies: those with aberrant origin of one or more coronary arteries and those with a fistular communication between a coronary artery and a cardiac chamber or another vessel.

Transoesophageal echocardiography, with its improved view of the structures at the base of the heart, provides a novel method to assess the coronary artery ostia and their proximal portion. ${ }^{2-4}$ This imaging technique is potentially useful for both the identification of anomalous coronary arteries and the accurate assessment of their anatomical course. The complementary role of transoesophageal echocardiography to coronary angiography 

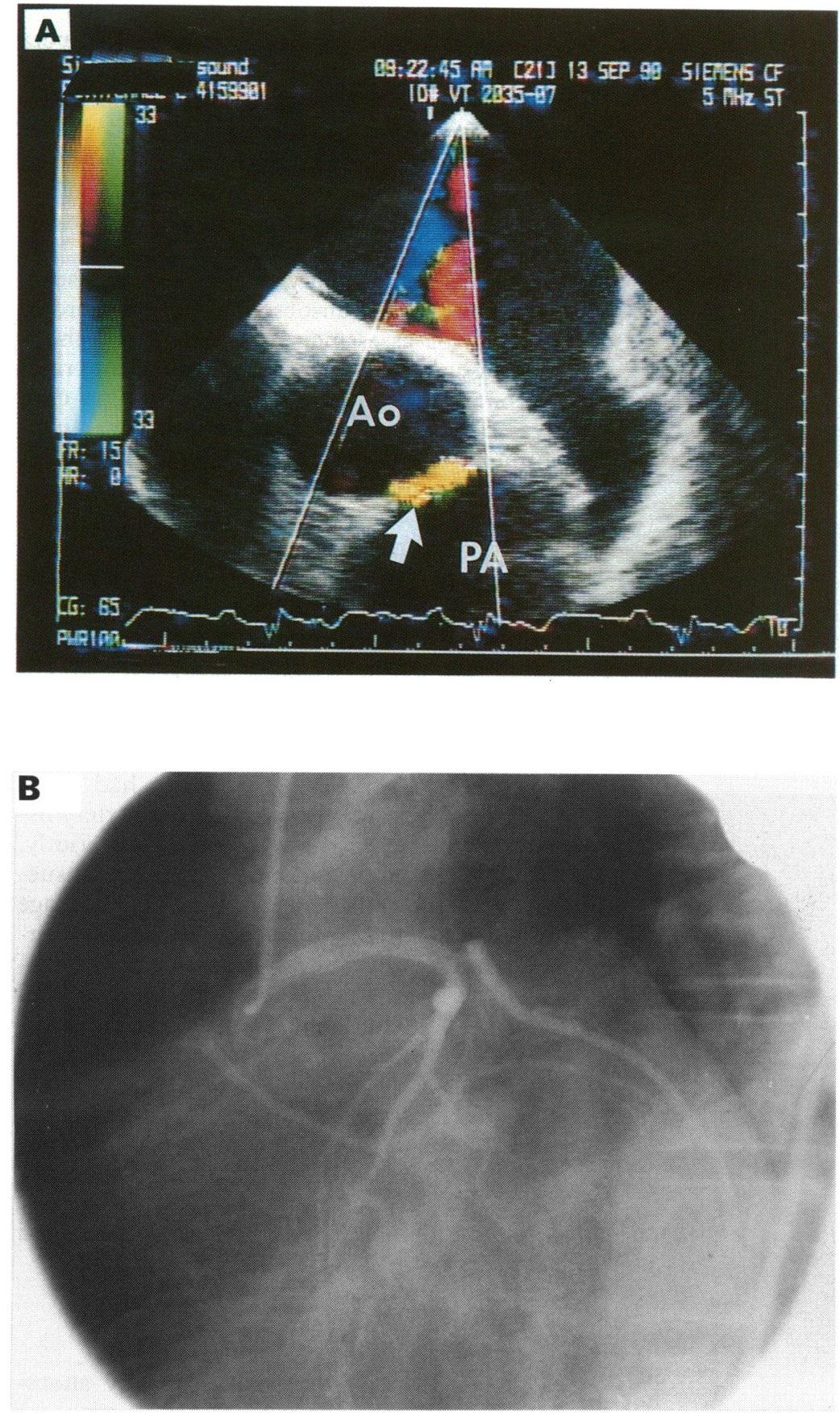

Figure 1 (A) Transoesophageal echocardiographic scan sectioning the great arteries in short axis. The aberrant left coronary artery (arrow) coursing between the two great arteries is shown well by colour flow imaging. Ao, aorta; $P A$, pulmonary artery.

(B) Coronary angiography shows the aberrant origin of the left coronary artery from the right coronary sinus.
2.5 to $3 \cdot 75 \mathrm{MHz}$. Transoesophageal studies with a $5 \mathrm{MHz}$ single plane probe were per- formed as previously described. ${ }^{5}$

The right and left coronary ostia were routinely seen during the transoesophageal study. The coronary arteries were sequentially seen by imaging at the level of the aortic root, initially in a short axis view, and manipulating the transducer with a combination of probe tip flexion, side to side tip translation, and rotation to follow their proximal course. ${ }^{4}$ When a coronary artery anomaly was identified the origin, course, and drainage site were closely examined. Colour flow imaging was used to aid location of the course of a tortuous coronary fistula.

\section{Results}

Eight patients were found to have coronary artery anomalies. Of these six had coronary angiography and a comparison of angiographic with transoesophageal echocardiographic findings in these patients forms the basis of this report. Table 1 shows the clinical features of these six patients. The two patients who did not undergo coronary angiography had a fistula from the circumflex artery to either the coronary sinus or the left atrium, and are not discussed further.

Of the six patients studied, the coronary anomaly was discovered during prior angiography in four patients (patients 1 to 4), was suspected due to an abnormal transthoracic echocardiographic study in patient 5 , and was discovered incidentally during transoesophageal echocardiography in patient 6 . Patients 5 and 6 subsequently had coronary angiography.

\section{CORRELATION BETWEEN ECHOCARDIOGRAPHY} AND ANGIOGRAPHY

Table 2 shows a summary of the echocardiographic and angiographic findings. There were two aberrant origins of a left coronary artery: one from the right sinus of Valsalva (patient 1) and the other from the main pulmonary artery (patient 5). The remaining four patients had fistulas: one involved the right coronary artery as the feeding vessel and drained into the superior vena cava (patient 6 ), and the remaining three involved the circumflex artery draining into the left ventricle in one case (patient 2) and into the right pulmonary artery in two cases (patients 3 and 4).

Transoesophageal echocardiography identified the origin of the right coronary artery in all cases and the left coronary artery in five cases. The left coronary artery was not seen in the single case where it arose aberrantly from the main pulmonary artery. The coronary artery fistulas were correctly assessed in all four patients. Their courses were followed and the drainage sites accurately identified in all cases.

In the four cases where the coronary artery anomaly was detected by prior angiography, transoesophageal echocardiography was performed specifically to obtain further anatomical detail. In patient 1 the ectopic origin of
Transthoracic echocardiography was formed in all cases. Various commercially available systems (Hewlett-Packard, Toshiba, and Siemans) were used. Transthoracic studies were performed from standard windows with phased array transducers ranging from 

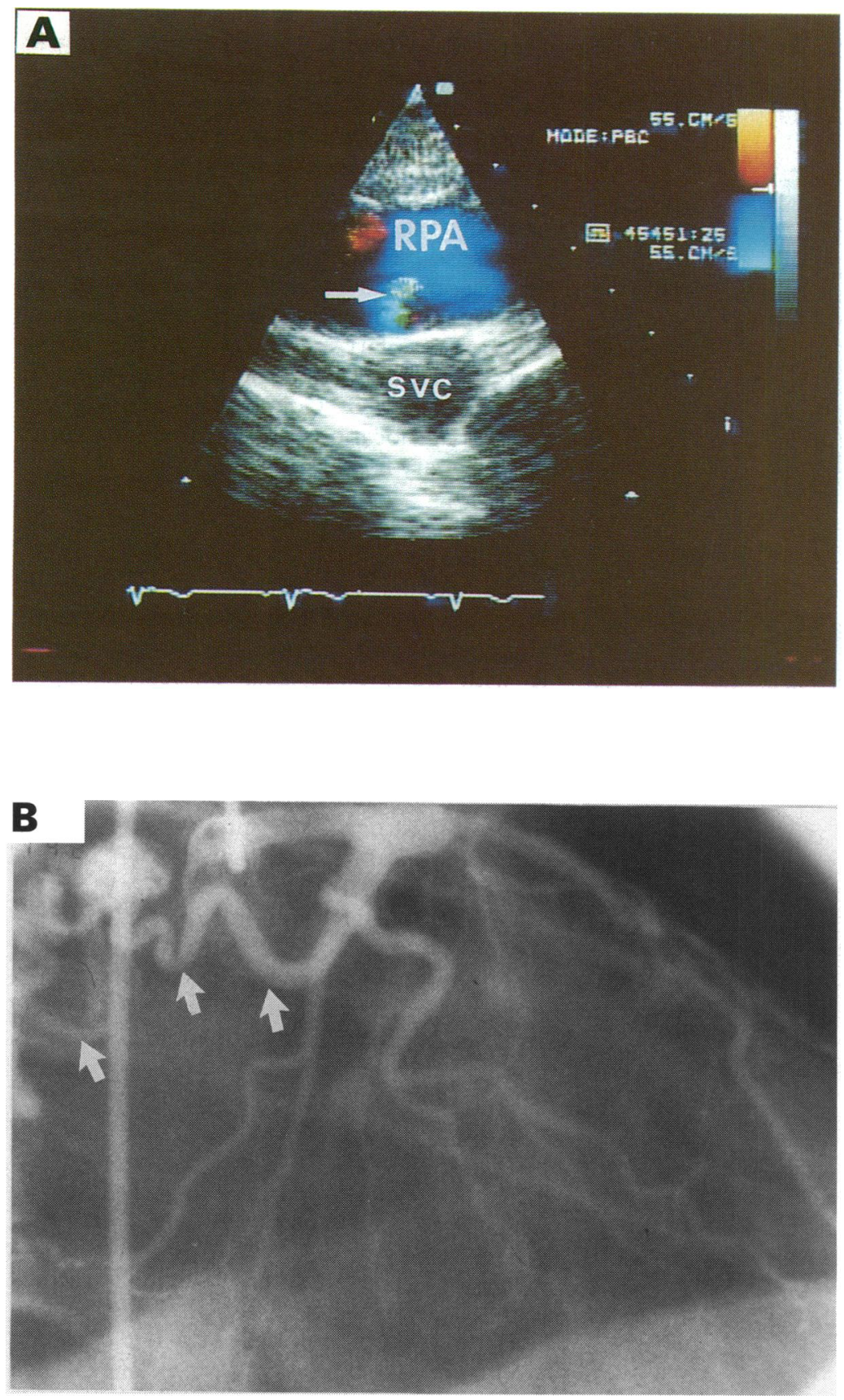

Figure 2 (A) Transoesophageal echocardiographic colour flow scan of the right pulmonary artery shows the drainage site of the coronary artery fistula (arrow). The origin and course of the fistula are identified on different imaging planes. $R P A$, right pulmonary artery; $S V C$, superior vena cava. (B) Coronary angiogram of the coronary artery fistula (arrows) shows the posterior course but the exact drainage site cannot be determined.

the left coronary artery arising from the right sinus of Valsalva was clearly identified on angiography, but its exact course in relation to the great vessels could not be determined with certainty. Transoesophageal echocardiography showed that the left coronary artery coursed between the aorta and the main pulmonary artery (fig 1 ). In patients 2,3 , and 4 , the coronary fistulas were correctly identified by angiography, but the exact drainage sites could not be confirmed. Transoesophageal echocardiography located the drainage sites in all three cases. Figure 2 shows the findings in patient 3 . In patients 5 and 6 , coronary angiography was performed after transoesophageal echocardiography. In patient 5, an ectopic origin of the left coronary artery was not seen during the transoesophageal echocardiographic study, but as no left main ostium was identified originating from the aorta and the right coronary artery was greatly dilated ectopic origin of the left coronary artery was suspected. Angiography confirmed the ectopic origin of the left coronary artery arising from the main pulmonary artery. Considerable collateralisation between the right and left coronary arteries was also seen. Patient 6 had transoesophageal echocardiography for assessment of aortic valve endocarditis. A fistula communicating the right coronary artery with the superior vena cava was detected incidentally and this was confirmed by subsequent angiography (fig 3). A shunt ratio of $1 \cdot 2: 1$ was found.

SURGICAL OUTCOME

All six patients underwent surgery and the findings were confirmed in five patients. In patient 1, bypass grafts were constructed from the aorta to the branches of the left coronary artery. In patient 3 the fistula was successfully closed at its drainage point on the right pulmonary artery, which was easily accessible. In patient 4 , who also had a circumflex artery to a right pulmonary artery fistula, the drainage site was located posteriorly. A previous surgical attempt had been unsuccessful at locating and ligating its drainage site. Intraoperative transoesophageal echocardiography guided the surgical team in locating the fistula and led to its successful closure. Patient 5 underwent surgical correction by ligation and bypass grafting of the left main coronary artery, which originated from the main pulmonary artery. In patient 6 the right coronary artery fistula was successfully closed at the time of aortic valve replacement. In patient 2 , the main indication for surgery was considerable coronary artery disease and at surgery the fistula could not be identified.

\section{Discussion}

Clinical diagnosis of coronary artery anomalies is difficult. Often there are no signs or symptoms and they are discovered as incidental findings at the time of catheterisation. ${ }^{1}$ Others are identified when they cause a continuous murmur, myocardial ischaemia, congestive heart failure, or endocarditis.

\section{TRANSTHORACIC ECHOCARDIOGRAPHY}

Transthoracic echocardiography may identify the origin of coronary arteries in selected patients. The left main coronary artery is most easily seen, and is identified in $58 \%$ $99 \%$ of patients. ${ }^{67}$ Although the course and drainage sites of anomalous coronary arteries can be visible from the transthoracic approach, success may be a function of patient age and size ${ }^{8}$ and has been described in paediatric populations ${ }^{89}$ where the acoustic window is optimum. A recent study of predominantly adult patients showed a high success rate with transthoracic colour flow imaging to identify drainage sites of fistulas, ${ }^{10}$ but other reports have shown limitations of

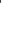

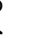

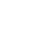
$\longrightarrow$ . $\vec{\omega}$ $\nabla$

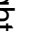



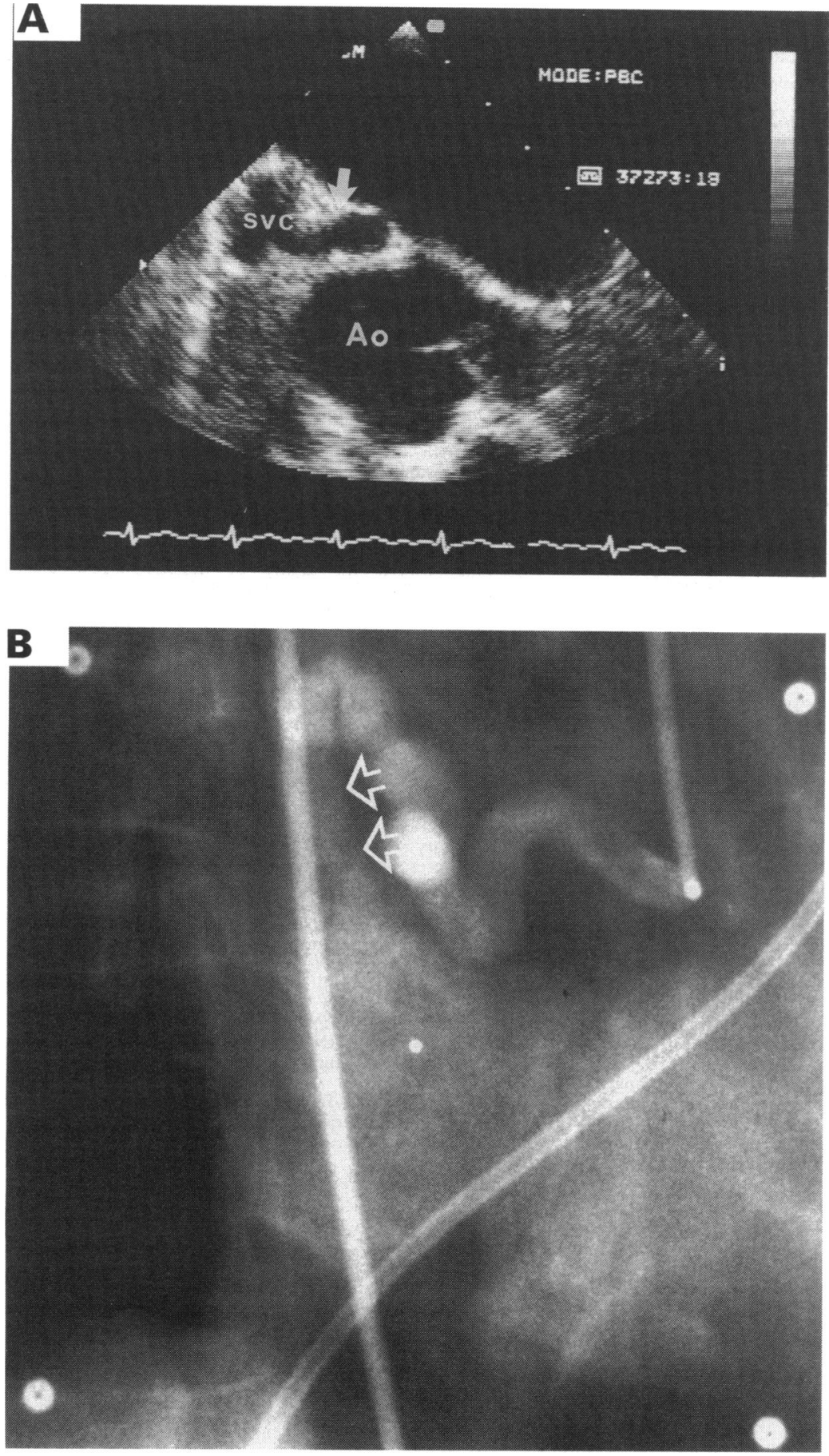

Figure 3 (A) Transoesophageal echocardiographic scan shows the tortuous and dilated coronary artery fistula (arrow) draining into the superior vena cava. Ao, aorta; SVC, superior vena cava. (B) Coronary angiogram shows the coronary artery fistula communicating with the superior vena cava (open arrows).

this approach both in patients with coronary artery fistulas ${ }^{11} 12$ and in patients with anomalous coronary vessels. ${ }^{13} 14$

TRANSOESOPHAGEAL ECHOCARDIOGRAPHY

The advantages of the transoesophageal approach include the proximity of the transducer to the area of interest as well as higher frequency transducers that allow better spatial resolution and assessment of detail. When specifically searching for coronary arteries, transoesophageal echocardiography can identify the left main coronary artery in $77 \%$ $100 \%$ and the right coronary artery in
$26 \%-100 \%$ of cases. ${ }^{3415}$ Often the left main coronary artery can be traced to its bifurcation where portions of the left anterior descending and circumflex arteries can be seen. The right coronary artery may also be traced for part of its proximal course. ${ }^{34}$

The superior imaging of the proximal coronary arteries from the oesophageal window makes transoesophageal echocardiography particularly useful in patients with an ectopic origin of a coronary artery or a coronary artery fistula, where dilatation of part or whole of the coronary tree is common. Colour flow imaging can further aid in the location of the origin, course, and drainage site of these abnormal vessels. Our experience suggests that the course of a dilated coronary artery or fistula can be readily identified by this imaging technique, a finding suggested by recent case reports ${ }^{121617}$ and short series. ${ }^{1113}$

Coronary angiography remains the gold standard for imaging the coronary tree ${ }^{1}$ by providing high quality images of both proximal and distal coronary arteries, identifying occlusive disease, and allowing views of collateral vessels. Nevertheless, transoesophageal echocardiography was found to have a complementary role even in those patients with angiographically proved coronary artery anomalies. Coronary angiography successfully showed the ectopic origin of the left coronary artery in both patients 1 and 5, but only transoesophageal echocardiography accurately found the course of the anomalous vessel between the aorta and pulmonary artery in patient 1 . Coronary angiography may also fail to detect the drainage site of a coronary fistula. ${ }^{12}$ In this selected series of patients transesophageal echocardiography was performed to help locate the course and drainage site of fistulas in three patients. In each case transoesophageal echocardiography was able to provide that information, which is important in planning the optimal surgical approach and determining the need for cardiopulmonary bypass. ${ }^{19} 20$ In patient 4 , in whom the fistula had not been found during previous surgery, intraoperative transoesophageal echocardiography located the drainage site in the posterior right pulmonary artery, and allowed successful ligation.

\section{LIMITATIONS OF TRANSOESOPHAGEAI} ECHOCARDIOGRAPHY

Although transoesophageal echocardiography views proximal coronary arteries and their abnormalities well some limitations remain. The ability to trace a segment of a coronary artery or a fistula may be limited by the position of the transducer (especially with single plane probes), cardiac motion, and the curvilinear nature of the vessel along the epicardial surface, which impairs the view of distal segments unless considerably dilated. Collateral vessels, usually of small calibre, are not seen and underlying occlusive coronary disease cannot be accurately assessed.

In conclusion transoesophageal echocardiography serves a useful role complementary 
to angiography in the assessment of coronary artery anomalies. It can locate and delineate the course of an ectopic coronary artery and the drainage site of a coronary fistula. When a coronary artery fistula is present, a dilated feeder vessel with an abnormal flow pattern can be readily identified. Transoesophageal echocardiography not only confirms the presence of coronary artery anomalies detected by angiography, but can also provide unique anatomical information that may have an impact on management. Conversely, angiography should be considered when a coronary artery anomaly is detected by transoesophageal echocardiography to provide better delineation of the distal coronary vessels, to find the degree of collateralisation, and to identify any coexistent occlusive coronary disease. In this clinical setting, these two imaging techniques are indeed complementary. As technology improves and application of biplane and multiplane transoesophageal echocardiographic probes become widespread, further improvements in the ability to assess coronary artery anomalies will be possible.

1 Yamanaka O, Hobbs RE. Coronary artery anomalies in 126,595 patients undergoing coronary arteriography. Cathet Cardiovasc Diagn 1990;21:28-40.

2 Seward JB, Khandheria BK, Oh JK, et al. Transesophageal echocardiography: technique, anatomic correlations, implementation and clinical applications. Mayo Clin Proc 1988;63:649-80

3 Zwicky P, Daniel WG, Mugge A, Lichtlen PR. Imaging of coronary arteries by colour-coded transesophageal Doppler echocardiography. Am $\mathcal{f}$ Cardiol 1988;62: 639-40.

4 Pearce FB, Sheikh KH, deBruijn NP, Kisslo J. Imaging of the coronary arteries by transesophageal echocardioof the coronary arteries by transesophageal ech

5 Chan KI Am Soc Echocardiogr 1989;2:27-83. Complications of transesophageal echocardiography in ambulatory adult patients: analysis of 1500 consecutive patients. F Am Soc Echocardiogr 1991;4:577-82.

6 Weyman AE, Feigenbaum H, Dillon JC, Johnston KW, Eggleton RC. Noninvasive visualization of the left main coronary artery by cross-sectional echocardiography. Circulation 1976;54:169-74.

7 Douglas PS, Fiolkoski J, Berko B, Reichek N. Echocardiographic visualization of coronary artery anatomy in the adult. $\mathcal{f} \mathrm{Am}$ Coll Cardiol 1988;11: 565-71.

8 Jureidini SB, Appleton RS, Nouri S. Detection of coronary artery abnormalities in tetralogy of Fallot by twodimensional echocardiography. F Am Coll Cardiol 1989; 4:960-7

9 Velvis H, Schmidt KG, Silverman NH, Turley K. Diagnosis of coronary artery fistula by two-dimensional echocardiography, pulsed Doppler ultrasound and color flow imaging. $\mathcal{F}$ Am Coll Cardiol 1989;14:968-76.

10 Shakudo M, Yoshikawa J, Yoshida K, Yamaura Y. Noninvasive diagnosis of coronary artery fistula by Doppler colour flow mapping. I Am Coll Cardiol 1989; 13:1572-7.

11 Samdarshi TE, Mahan EF III, Nanda NC, Sanyal RS. Transesophageal echocardiographic assessment of conTransesophageal echocardiographic assessment of congenital coronary artery to coronary

12 Calafiore PA, Raymond R, Schiavone WA, Rosenkran ER. Precise evaluation of a complex coronary arteriovenous fistula: the utility of transesophageal color Doppler. $\mathcal{A}$ Am Soc Echocardiogr 1989;2:337-41.

13 Gaither NS, Rogan KM, Stajdunar K, et al. Anomalous origin and course of coronary arteries in adults: identification and improved imaging utilizing transesophageal echocardiography. Am Heart $\mathcal{f}$ 1991;122:69-75.

14 Salloum JA, Thomas D, Evans J. Transoesophageal echocardiography in diagnosis of aberrant coronary artery. Int 7 Cardiol 1991;32:106-8.

15 Yamagishi M, Miyatake K, Beppu S, et al. Assessment of coronary blood flow by transesophageal two-dimensioncoronary blood flow by transesophageal two-dimensional pulsed Dopp

$16 \mathrm{Kwang} \mathrm{KK}$. Confirmation of anomalous origin of the right coronary artery from the left sinus of Valsalva by means of transesophageal echocardiography. Am Heart $\mathcal{F} 1991$; 122:851-4

17 Smolin MR, Gorman PD, Gaither NS, Wortham DC. Origin of the right coronary artery from the left main coronary artery identified by transesophageal echocardiography. Am Heart f 1992;123:1062-5.

18 Reeder GS, Tajik AJ, Smith HC. Visualization of coronary artery fistula by two-dimensional echocardiography. Mayo Clin Proc 1980;55:185-9.

19 Lowe JE, Oldham HN Jr, Sabiston DC Jr. Surgical management of congenital coronary artery fistulas. Ann Surg agement of congen

20 Kirklin JW, Barrat-Boyes BG. Congenital anomalies of the coronary arteries. In: Kirklin JW, Barrat-Boyes BG, eds. Cardiac Surgery. New York: John Wiley, 1986: 945-69. 